\title{
Dermatology within the UK podiatric literature: a content analysis (1989-2010)
}

\author{
Ivan R Bristow ${ }^{*}$ and Alan M Borthwick
}

\begin{abstract}
Background: Although dermatology, as a medical subject, has been a facet of the training and education of podiatrists for many years, it is, arguably, only in recent years that the speciality of podiatric dermatology has emerged within the profession. Some indication of this gradual development may be identified through a content analysis of the podiatric literature in the UK, spanning a 21 year timeframe.

Method: 6 key professional journals were selected for content analysis in order to provide a picture of the emergence and development of podiatric dermatology over a period extending from 1989 to 2010. Both syntactical and thematic unitization were deployed in the analysis, revealing both manifest and latent content. Categories were devised using a prior coding, a codebook produced to define relevant concepts and category characteristics, and the coding scheme subject to an assessment of reliability.

Results: 1611 units appeared in the 6 journals across a 21 year timeframe. 88\% ( $n=1417)$ occurred in one journal (Podiatry Now and its predecessors). Modal categories within all journals included course adverts $(n=673)$, commercial adverts $(n=562)$ and articles by podiatrists $(n=133)$. There was an overall rise from 40 per annum in 1989, to over 100 in 2010. A wider range of dermatological topics were addressed, ranging from fungal nail infections to melanoma.

Conclusions: It is evident from this analysis that there has been an increasing focus on dermatology as a topic within the main podiatric journals in the UK over the last 21 years, primarily reflecting a rise in commercial advertising and an increase in academic dermatology related publications. Whilst earlier publications tended to focus on warts and fungal infections, more recent publications address a broader spectrum of topics. Changes in prescribing rights may be relevant to these findings, as may the enhanced professional and regulatory body requirements on continuing professional development.
\end{abstract}

Keywords: Dermatology, Podiatry, History, Content analysis

\section{Background}

Throughout the history of chiropody/podiatry in the United Kingdom, links to dermatology are evident within the professional literature. As a subject, it is evident as part of the UK chiropody curriculum since the inception of the first school in 1919 - initially as a subject delivered by visiting dermatologists and physicians and latterly, following the formation of the Society of Chiropodists, when formalization of the syllabus occurred in the 1950's [1-3].

\footnotetext{
* Correspondence: ib@soton.ac.uk

Faculty of Health Sciences, University of Southampton, Southampton SO17
} 1BJ, UK

\section{() Biomed Central}

(c) 2013 Bristow and Borthwick; licensee BioMed Central Ltd. This is an Open Access article distributed under the terms of the Creative Commons Attribution License (http://creativecommons.org/licenses/by/2.0), which permits unrestricted use,

distribution, and reproduction in any medium, provided the original work is properly cited.
1945) the journal entitled "The Chiropodist" a professional podiatric journal of the Society of Chiropodists \& Podiatrists had published over 50 papers on the subject of dermatology [4]. Virtually all of these papers were written by eminent dermatologists of the time such as MacKenna [5], Bettley [6], Ryan [7], Grant-Peterkin [8], Champion [9] and Williams [10]. Moreover, all of the papers were reprints from medical journals. As an editorial explained at the time, this was a sad reflection of the lack of research publications from within the chiropody profession [11] during this period. Records from this period demonstrate that dermatologists were also 
frequently invited to speak at Annual Conventions of the Society [12-16].

In 1975, the Society of Chiropodists had recognised the number of specialist interest groups emerging with a common interest in progressing technical skills (particularly podiatric surgery). As a consequence, a Postgraduate Board was assembled that year, consisting of representation from the Faculty of Anaesthesia, Podiatry Association and the Royal College of Physicians, to review and approve courses and as a means of ensuring quality standards, patient safety and insurance cover $[17,18]$. At the end of the decade and into the early 1980's, chiropodists were increasingly being recognised as developing specialities in the care of the diabetic foot [19], ischaemic limbs [20] and "biomechanics" [21] facilitated by the increase in postgraduate courses available [22]. Towards the end of the 1980's, development of these specialities were well established, in part, possibly driven by the new degree status awarded to the profession around this period [23]. A survey conducted in 1987 examined the expectations of chiropody students, and high numbers had aspirations upon graduation to work within these specialities [24].

Today, dermatology is taught at an undergraduate level both formally in the classroom and in the clinical setting. As with the medical model, demands for encompassing a wide range of areas in the professional curriculum have tended to side line the subject [25] despite the fact that skin problems on the foot are a common entity $[26,27]$ and much of a clinicians work is focussed on treating skin related pathologies. Expanding roles within podiatry, as evidenced by the recent acquisition of rights to independent prescribing of medicines in both the UK and Australia, alongside a growth in other effective management therapies for disorders of the skin new to podiatry, further emphasise the need for good diagnostic and therapeutic skills. This paper aims to profile the development of dermatological knowledge within the UK podiatry profession, subsequent to the introduction of degree programmes in podiatry for a period of 21 years (1989-2010).

\section{Methodology}

In order to build up an objective picture of the development of dermatology within podiatry data was obtained from published documentary evidence. Professional journals could be determined as covering a number of functions as outlined by Lundberg [28], providing a rich source of documentary evidence:

1. Provide peer-reviewed scientific and clinical evidence.

2. Hold an educational role.

3. Maintain practitioners' awareness of contemporary issues within the profession.
4. Inform practitioners about non-clinical issues including politics, ethics and history.

5. Forecast future trends.

6. Provide basic background in science and research.

7. Act as a bridge between the textbook and the clinic.

The research questions were as follows:

1. What is the extent and coverage of dermatology within the selected journals (1989-2010)?

2. How has dermatological coverage changed during the study period?

Journals included for analysis consisted of the mainstream professional literature, available to UK registered chiropodists/podiatrists during the periods given below. Although relevant articles are published in other journals, the publications included here are recognized by professionals and are clearly identified within the field. Therefore, it should be expected to reflect, singularly and more accurately, the development of dermatological practice in chiropody/podiatry:

1. Podiatry Now (and its former titles - The Chiropodist and The Journal of British Podiatric Medicine): 1989 - 2010

2. The Foot (commenced in 1991): $1991-2010$

3. Search News (ceased publication in 1997): $1990-1997$

4. British Journal of Podiatry (Commenced 1998 and ceased publication in 2007): $1998-2007$

5. Journal of British Podiatric Medicine \& Surgery (ceased publication in 1997): 1989 - 1997

6. Journal of Foot and Ankle Research (E-journal commenced 2008): 2008-2010

The journals given above were subject to a wellestablished and widely applied method of documentary analysis known as content analysis [29]. Both a syntactical and thematic form of unitization was undertaken, centred on identifying keywords which could easily be replicated. Syntactical unitization is the identification of specific keywords which require little interpretation or judgement as to their meaning - for example words such as "dermatology" or "skin". Such terms are relatively simple and are less open to interpretation and therefore more reliable [29]. Thematic unitization allowed for analysis of text identifying the present of a concept or theme which may not be overtly evident [30], as being part of the terms of study such as "bullous Impetigo" or "sun awareness and the risk of skin cancer" for example. By combining both forms of unitization it permitted the content to be explored with greater depth for validity and understanding within a reference frame 
of dermatology and ensured that both manifest and latent content were assessed [31].

Categories were devised in a manner as described by Weber [32] using a technique of a priori coding [33] where categories were determined prior to the analysis. In order to gain context to the data, categories were constructed by the author to be meaningful, reflecting the different aspects of the journal function, for example:

- Editorial: Reflecting the political views of the professional body.

- Correspondence: Expressing the issues of the readership.

- Advertisements: Illustrating current trends in industry.

- Articles by Podiatrists: Current areas of publications and research.

- Conference Abstracts: Representing special interest groups.

- News: Current issues of political, professional or personal interest.

To reduce ambiguities, a codebook was produced clearly defining the concept under analysis and individual category characteristics. The coding scheme was then tested by analysing a sample of text. This was undertaken to verify that the categories held a clear definition ensuring exclusivity and that all data was exhaustive.

Following the testing stage, each journal in the specified range was read and any reference or commentary related to dermatology was noted and placed into one of the categories. The timeframe across which this study ran was determined as twenty-one years, reflecting the time the author has been registered.

Inclusion criteria for the analysis included any themes relating to skin disorders affecting the feet. Themes were excluded if they related to routine palliative procedures for nails, corns and callus as implied in the definition given by Farndon et al. [34] as this represents a function of "core" podiatry/chiropody skills. To prevent overlap into areas of wound care and diabetes care any themes related to common diabetic skin manifestations (vascular and neurological processes) were excluded from the analysis. Coding of the data were undertaken exclusively by the authors.

\section{Intercoder reliability}

To ensure basic stability of the coding scheme, an assessment of reliability was undertaken employing the use of a second (independent) coder trained in content analysis - a process termed reproducibility [35]. An entire journal was purposively selected and coded by the second coder to test reproducibility. This journal represented around $8.5 \%$ sample of the total items coded.
The data from the two coders was then calculated using Krippendorff's alpha $(\alpha)$ statistic. Although many different tests are available, this test is widely used and considered robust, taking into account chance agreement and, in addition, the magnitude of disagreements, adjusting also for the type of variable type (nominal, ordinal etc.)[35-37] which is not addressed by other reliability measures [38].

The Krippendorff's alpha statistic ranges from .00 (no agreement) to 1.00 (perfect agreement) demonstrating a high level agreement from the data. Krippendorff's alpha $(\alpha)$ statistic was calculated using the SPSS Statistics Package version 17 (SPSS Inc, USA) and the customized SPSS macro for Krippendorff's alpha [37]. Reproducibility for this data were reported as 0.9727 - very high, indicating a high level of agreement between coders.

\section{Findings}

In the period from 1989-2010, a total of 1611 units appeared in the 6 journals analysed. The division of the units across the publications is given in Figure 1. Of these 88.0\% ( $\mathrm{n}=1417)$ occurred in one journal - Podiatry Now (and its former titles) with just $12.0 \%(\mathrm{n}=194)$ spread across the remaining five journals.

The modal categories within all journals were course advertisements/reports $(n=673)$ followed by commercial advertisements $(\mathrm{n}=562)$ and articles by podiatrists $(n=133)$. Over the study period a gradual increase in the number of references to dermatology was shown to rise from an average of around 40 per annum in 1989 to over 100 in 2010 (Figure 2).

\section{Search journal}

The journal "Search" ran for 7 years from 1990 until being integrated into Podiatry Now [39] and was circulated primarily to managers within the NHS consequently little dermatological content was evident. In the latter half of its publication years, a number of short news items were published including reporting trials from medical research on warts [40], psoriasis [41], melanoma [42] and new products [43]. Only three dermatological
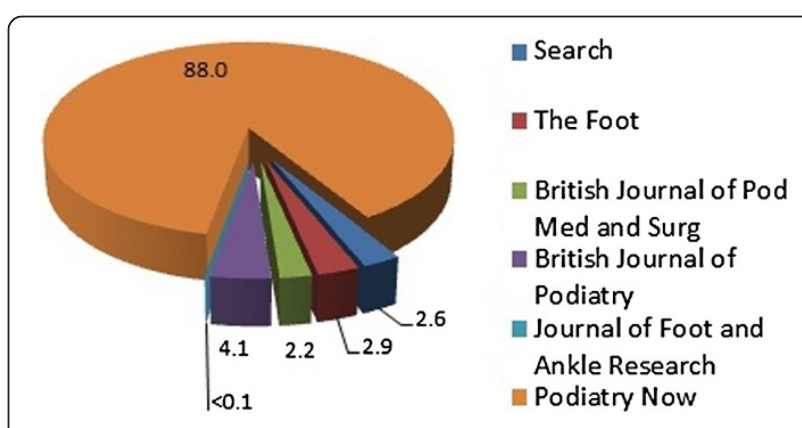

Figure 1 Total journal share (\%). 




papers appeared in the journal written by podiatrists; on the topics of fungal nail treatments [44], urea based emollients [45] and dry skin [46] and were generally small NHS departmental studies. Latterly, mentions of the dermatology were made when discussing the development of continuing professional development programmes in 1996 [47].

\section{The British journal of podiatric medicine and surgery}

The British Journal of Podiatric Medicine and Surgery (BJPMS) was the official journal of the Podiatry Association (PA), published up until 1997 when it became part of the British Journal of Podiatry [39]. The PA was predominantly a group representing the interests of podiatric surgeons within the UK. Despite its surgical leanings, a small number of references to dermatological papers published in medical journals are made on topics such as onychomycosis and melanoma [48]. The topic of antifungals and steroid creams also occurs when discussions are made on prescription rights in 1996 [49]. As expected papers on nail surgery are evident, albeit in small numbers $(n=3)$ in the 7 year period.

\section{The foot journal}

The Foot (fully titled "The Foot - the International Journal of Clinical Foot Science") differed from all the other podiatry journal analysed in this study as it is the only one which the editorial board is shared with another professional group; orthopaedic surgeons. The journal was launched in 1991 and was originally distributed with Society of Chiropodists members' subscription free of charge until around 2001. It was hoped to showcase graduate research and become an academic journal with Index Medicus status [39,50] and establish an impact factor something at the time which had eluded all UK podiatric journals [51]. Analysis of its content revealed a total of 32 dermatological related papers. Of these 14 were published by medics and focussed primarily on skin tumours and common foot infections [52-65] whilst podiatry lead author papers focused on mycoses [66-71], wart infections
[72-74], electrosurgery [75,76] and epidemiology [77]. Interestingly, other single papers by Podiatrists focused on less commonly encountered dermatological conditions [78-82]. Three papers were investigations into the pathology of corns and callus [83-85]. Nail surgery was a topic of eight papers [86-93]. Minimal course advertisements and commercial advertising were evident in this academic publication.

\section{British journal of podiatry}

The British Journal of Podiatry began in 1998, comprising of the two former journals - The Journal of British Podiatric Medicine and the British Journal of Podiatric Medicine and Surgery intending to carry editorials, refereed articles and professional information. In its 10 year history, 20 dermatological papers were identified written by Podiatrists with an additional 4 on nail surgery [94-97]. Areas of dermatological focus included warts [98-101], fungal infections [102,103], case studies on tumours and unusual infections [104-110]. Four studies looked at more academic areas and laboratory work relating to dermatology [111-114]. Two papers looked at treatments for skin conditions $[115,116]$.

\section{Journal of foot and ankle research}

Less than $0.1 \%$ of all units occurred in this journal, explained by its three year lifespan during the study period. Only five publications were evident in the online journal. Four these were on the subject of melanoma, submitted by the author [117-120] whilst one paper studied the epidemiology of callus patterns in the elderly [121].

\section{Podiatry Now}

This journal represented the vast majority of units (1417, 88\%) within this analysis. In part this may be explained by its longevity compared to the other journals - none of which covered the entire period of study but also a reflection of the functions and audience types of each of the journals analysed. Podiatry Now as a professional journal covered many of the categories identified in this study when compared to the other publications which tended to focus more on academic papers only or one particular aspect of practice - podiatric surgery for example. The modal categories, within this journal, were course advertisements (699) and commercial advertisements (522) over 21 years. A full breakdown is given in Figure 3 .

Throughout the twenty-one years, 77 dermatology related articles, authored by podiatrists, have been published in the journal. The publication rate has remained at a constant level averaging around 3-4 a year. The focus of the articles has varied slightly over this period. In the earlier years the attention has been on traditional skin problems such as warts [122-125], fungal infections 


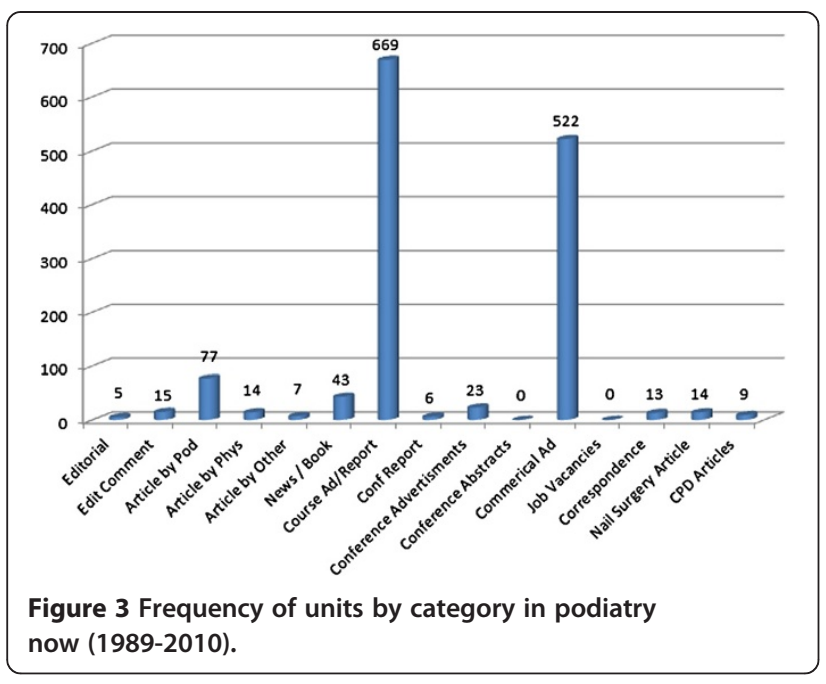

[126-128] as well as general articles on common dermatoses such as psoriasis $[129,130]$. At the end of the 1990's although papers on the traditional topics were still being covered [131-133], skin tumours became an interest with case studies emerging on melanoma [134], squamous cell carcinoma [135,136] and Bowen's disease [137]. At this time, inclusion of a section entitled "Clinical Picture Quiz" which invited authors to send in a clinical quiz for readers attracted a number of dermatological cases over the subsequent years [138-140] including eight from the author [141-148].

Physicians and other healthcare professionals published 14 and 7 dermatology related articles respectively in the journal. The majority of physician authored articles were reprints from other medical journals $(n=9)$ [149-157]. The reasons for this are unclear. It may reflect a lack of suitable podiatric literature during this period on the subject or an editorial decision to include broader knowledge which may be relevant to podiatrists.

Throughout the study time frame, editorial commentary and correspondence on dermatological themes were rare, particularly in the latter half of this period. In the early part of the period studied, discussion of various dermatological topics in editorial comment was mainly through the writing of Colin Dagnall. Dermatological topics were briefly discussed in his column in the journal (simply entitled "Dagnall") which ran until the December 1992 issue but also latterly by Dagnall through the correspondence pages. A few years on, references were made in the editorial about dermatological conditions such as fungal foot infections, warts and their treatments and were mentioned in the journal as part of the medianote section as well as occasional new product announcements. A small increase of the study period was also noted for news items and book reviews with an average of one unit per year in 1989, rising modestly to around 3 per year by 2010 .
Course advertisements on dermatological topics and reports from the data demonstrate a significant increase with time (see Figure 4), on average, doubling during the study period from 20 to over 40, whilst nail surgery courses had virtually ceased.

The increase in the number of course advertisements could be explained by a number of possible factors. First, as the Society has grown in its membership, the number of local branches has increased along with the amount of activity. To accommodate this, the journal may have increased the advertisement of locally run courses. More likely however, was the political climate and the Governments move to improve health care in the late 1990's. The paper entitled 'A First Class Service' [158] and subsequent communications [159] outlined the need for continuing professional development (CPD) within health care professions to maintain and improve quality as part of the clinical governance initiative [160]. The response from the Society of Chiropodists and Podiatrists was the launch of a programme of CPD modules in 2001 for its members [161] including a dermatology module, written by the author [162], which became a part of the core modules offered in 2003 [163]. Latterly, the introduction of mandatory CPD was placed on chiropodists and podiatrists with the introduction of the Health Professions Council (HPC) biennial audit cycles which began in 2006 [164]. Prior to the changes in the CPD process in 2003, only eight individual study days on dermatology had been advertised as update courses to members in the preceding 14 years but following the introduction of the topic as a core subject the numbers of advertisements for such courses increased dramatically to 15 courses in the following 7 years. This trend was mirrored by an increase in the number of course reports which were published in the journal.

The outlier observed in Figure 4 (77 course advertisements in 2006) represented a year in which a large number of dermatological courses were being run whilst simultaneously being heavily advertised. The reason for this is not clear. However, increased advertising in this year may be a reflection of the introduction of mandatory

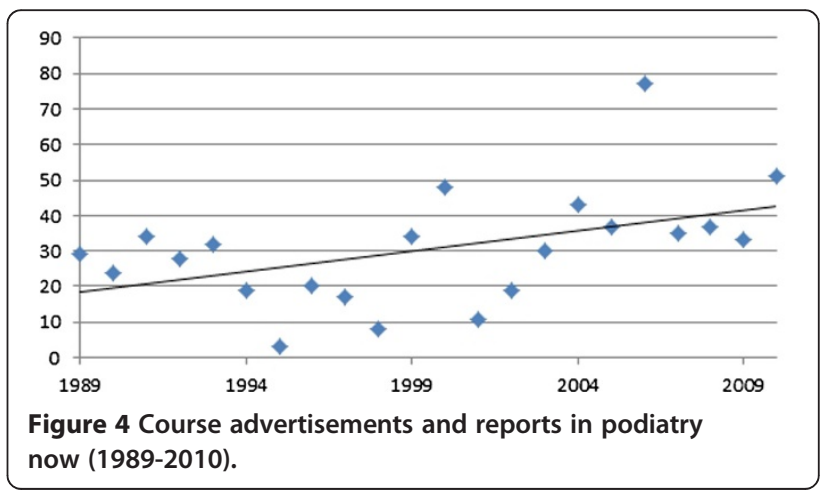


CPD by the Health Professions Council, influencing many local SCP branches to increase their educational provision for their members during this particular year. Similar but smaller increases were noted for the years 1999 (34) and 2000 (48). Both of these represent a disproportionate amount of advertising by an independent company for a course in electrosurgery. Other courses offering dermatological skills (cryosurgery) were identified. Both electrosurgery and cryosurgery courses were more frequently advertised in the first half of the study period suggesting that the need (or demand) for training in these modalities had decreased.

In 2004, inserts appeared within the journal Podiatry Now. These were published as update articles on various topics to enhance the availability of CPD to members [165]. Up until the end of 2010, nine articles had been published with a dermatological theme including fungal infections [166,167], warts [168], psoriasis and eczema [169], emollients [170], cryosurgery [171], electrosurgery [172], melanoma [173] and non-mechanical causes of hyperkeratosis [174].

As part of the CPD process, distance learning modules in dermatology were noted to be advertised monthly within the journal, offered by a private company from 2003 continuously until the end of the study period (Figure 5). It is assumed that such courses were advertised as an alternative means for podiatrists to receive $\mathrm{CPD}$, in particular for those in private practice who maybe geographically isolated or unable to travel to conferences and similar events. The steep rise in advertisements around 2005 maybe explained, once again, by the introduction of mandatory CPD for podiatrists at this time. The demise of the nail surgery course (Figure 6) could be explained as training in nail surgery techniques only became part of the undergraduate curriculum around the early 1980's, following the introduction of local anaesthesia [175]. This meant many chiropodists/podiatrists who qualified before this period would be required to undertake an approved course to acquire the appropriate skills.

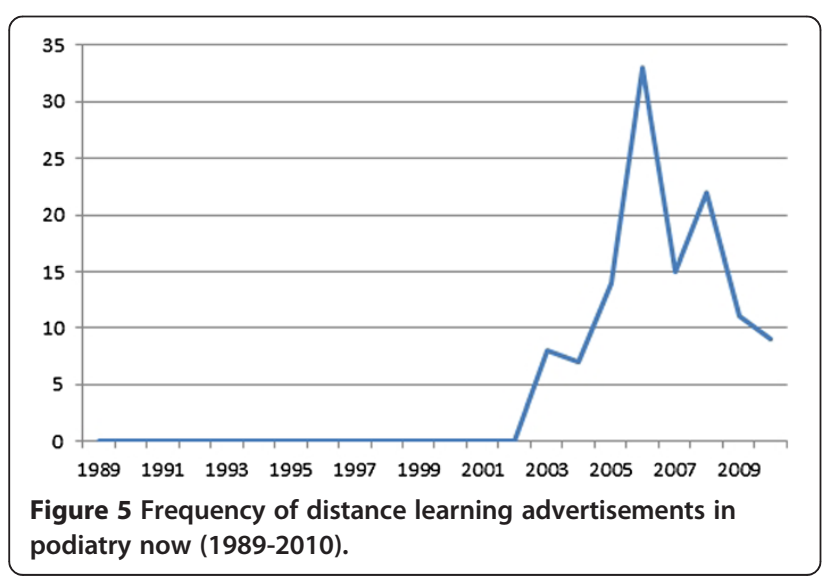

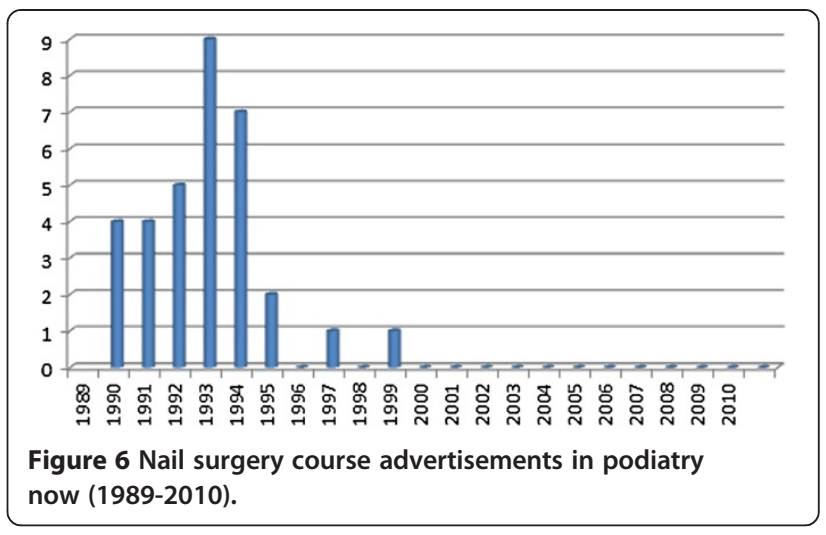

By 2000, one could assume that all those requiring training would have sought it during this period and hence there was no need to run further courses.

Over the study period, physicians were providing the majority of dermatological lectures within podiatry $(n=118)$, with nearly twice as many advertisements as Podiatrists ( $\mathrm{n}=60$ ) although an analysis of frequency counts suggested an increasing trend for more Podiatrists delivering lectures (Figure 7).

Many lectures by doctors were delivered at a local branch level by consultant dermatologists across the UK. The most frequent topics delivered were general dermatology of the foot and skin tumours/melanoma, when stated in the advertisement. The first conference dedicated wholly to podiatric dermatology was advertised in 2003 [176] and took place at the University College, Northampton. The conference ran for four years on annual basis and accounted for the conference advertising evident in the data from 2003 to 2006.

"Lectures by others" was a category used to denote advertised lectures on dermatological subjects not given by a podiatrist or physician (or occasionally, when the designation of the speaker was not stated). The majority of these were presentations on aspects of microbiology (particularly fungal infections) delivered by mycologists.

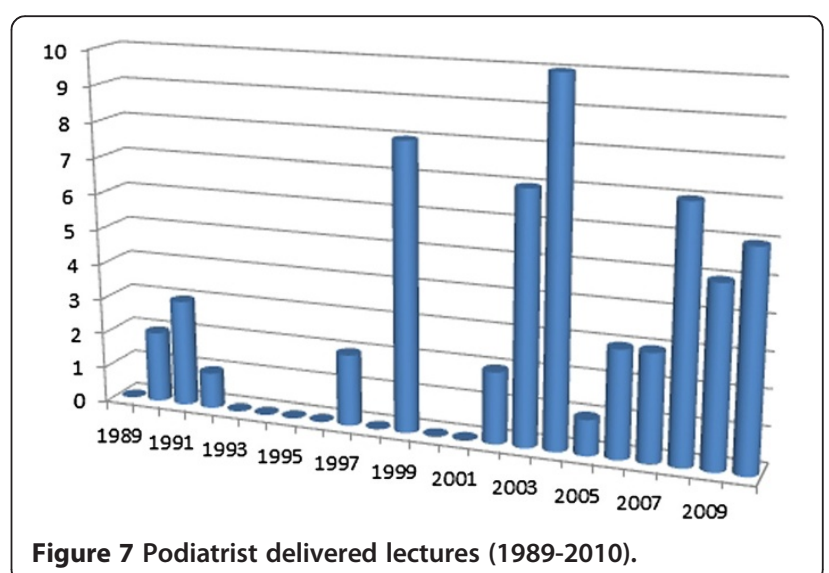


In addition, some related to prescription only medicines listed as given by a "company representative" (for products such as Loceryl $^{\oplus}$, Dovonex ${ }^{\oplus}$ and Sporanox ${ }^{\oplus}$ ) occurring across the whole of the study period.

Despite the raised profile of the dermatology within podiatry, it has rarely been advertised as a higher education module until recently - a total of five advertisements, with four being in the period 2007-2010 with modules offered by Universities across the UK (Universities of Stirling, Salford, and Sunderland with Glasgow Caledonian University and Queen Margaret University, Edinburgh).

\section{Commercial advertising in podiatry Now}

Throughout the 21 year period, analysis of the amount of dermatology related advertising demonstrated an increase in number products advertised to podiatrists. This can be seen as a few products advertised in 1989, rising to around an average of 40 annual advertisements by 2010 (see Figure 8).

Initial advertisements focused on cryosurgical equipment but this is quickly overtaken in two years by the promotion of emollient products focused on the foot. These continue to be the major part of dermatological advertising in the latter part of the study period. Other frequent products include topical salicylic acid $\left(\right.$ Occlusal $\left.^{\oplus}\right)$ preparations, topical antifungal and antiseptic agents (Mykored $^{\oplus}$, Crystacide $^{\oplus}$ and Monphytol $^{\odot}$ ). The majority of the advertising occurred within Podiatry Now which could be explained as its role as a professional journal reaching all members of the professional body, advertisers would be well aware of its circulation over the other journals mentioned. Particularly heavy periods of advertising are noted in the period $2002-2004$ which is a reflection of a few emollient and antifungal products being

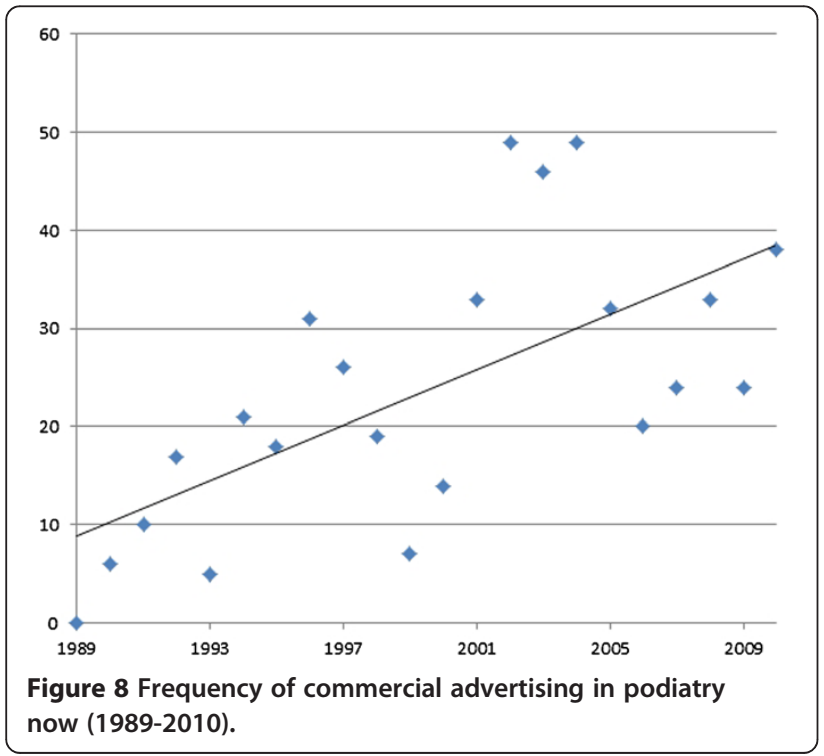

profoundly advertised within this period. The reasons for this are unclear.

\section{Prescription only medicines}

In 1994, the first prescription-only medicine (POM) was advertised to UK podiatrists within Podiatry Now. The drug Terbinafine $\left(\right.$ Lamisil $\left.^{\odot}\right)$ is an oral antifungal agent used in the treatment of tinea pedis and onychomycosis. Although UK podiatrists are not able to prescribe independently (just yet), access or supply this medication, the advertisement was carried. The motives of the pharmaceutical company are not clear but presumably this was based on the assumption that podiatrists encounter a lot of fungal foot disease and may consider referring on cases to general practitioners. Subsequently, this would actively promote the fact that a medication was available and ultimately raise awareness and prescriptions of the drug through the general practitioner. Following on in 1996, Itraconazole (Sporanox ${ }^{\odot}$ ) and Amorolfine nail lacquer (Locery $)^{\circledR}$ ) other prescription only medicines were included in the same journal and ran several marketing campaigns. To accompany this, a number of evenings were advertised in the journal, hosted and presented by pharmaceutical representatives promoting antifungal agents and treatments for psoriasis (Dovonex ${ }^{\odot}$ ) to podiatrists. Despite the move in recent years towards increased access to medicines and prescribing, with the introduction of patient group directions and supplementary prescribing for podiatrists, no other advertisements for prescription only medicines have appeared in the journal.

\section{Limitations of the study}

Content analysis is defined as a research technique for making replicable and valid inferences from texts (or other meaningful matter) to the contexts of their use [35]. Neuendorf [177] defines it as the systematic, objective, quantitative analysis of message characteristics. As a technique it can be useful to discover and describe the focus of social attention [32]. The technique allows the researcher to sift through large quantities of data systematically allowing the discovery of inferences and the examination of patterns and trends in documents [33]. This content analysis aimed to give an overview of dermatology and its development within podiatry for the period 1989-2010. In undertaking this, measures were taken to ensure that the data were representative and reliability tests were been undertaken to assess the coding procedure. A full analysis of the mainstream podiatry journals was conducted, rather than a sample, for this period in an attempt to capture the most complete picture

It must be acknowledged that this data can only represent what has been published within these journals and 
may not fully present the true picture. For example, many courses which have been run during this period may not have been advertised using this medium and so will not have been included. In addition, frequency counting as the sole form of analysis can be misinterpreted, therefore attempts have been made to further analyse the data in order to describe and explain any findings. Content analysis is inherently reductive when placing the data into categories. When defining boundaries and definitions for the key terms it is accepted that there will be material which could be considered borderline. The definition which has been adopted as it emphasizes core podiatry skills - the routine palliative procedures for nails, corns and callus acting as a delineation from dermatology. To prevent overlap into areas of wound care and diabetes any themes related to common diabetic skin manifestations (vascular and neurological processes) were excluded from the analysis. Subsequently, papers have been excluded although it could be argued contribute in a broader sense to dermatology and podiatry including the work of Springett [178], Potter [179,180] and Hashmi [113,181] along with much of the literature pertaining to the diabetic foot.

\section{Conclusions}

This content analysis set out to profile the coverage of dermatology within the mainstream podiatric literature from 1989-2010. From this analysis it is evident that there has been an increasing focus on dermatology as a topic within the main podiatric journals published in the UK. This has been predominantly as a rise in advertising of commercial products and increase in dermatology related publications. Nearly $90 \%$ of all references to dermatology appeared in one podiatry journal - Podiatry Now and its predecessors. Analysis of the papers published in the journals has shown work was predominantly authored by podiatrists and physicians, with a proportion of the latter featuring as reprints from other journals. Earlier publications from podiatrists tended to focus on traditional skin disorders of warts and fungal infections but more recently case studies and papers have emerged on other skin conditions. Educational and CPD opportunities in dermatology have increased in line with the changes to HPC re-registration and professional body CPD requirements.

\section{Competing interests}

Both authors declare that they have no competing interests.

\section{Authors' contributions}

IB was responsible for the original design of the study, along with initial data analysis and the drafting of the manuscript. $A B$ acted as second analyst of data and contributed to subsequent drafts of the paper. All authors read and approved the final manuscript.

Received: 21 March 2013 Accepted: 15 May 2013

Published: 24 May 2013

\section{References}

1. Ford HP: The development of chiropody. The Chiropodist 1951, 6:325-334

2. Read PJ: Education in chiropody. The Chiropodist 1964, 19:49-53.

3. Rosenstein $\mathrm{H}$ : The future of chiropody in the national health service. The Chiropodist 1959, 14:49-58.

4. Bristow IR: The origins and evolution of podiatric dermatology, PhD thesis. Southampton, United Kingdom: University of Southampton, Faculty of Health Sciences; 2011.

5. MacKenna RMB: Diseases of the skin in the elderly. The Chiropodist 1966, 22:266-276.

6. Bettley FR: Effects of soap on the skin. The Chiropodist 1959, 14:304-311.

7. Ryan TJ: Vasculitis. The Chiropodist 1978, 33:11-16.

8. Grant-Peterkin GA: Common skin infections of the feet. The Chiropodist 1947, 2:98-100.

9. Champion $\mathrm{RH}$ : Diseases of the skin - treatment of psoriasis. The Chiropodist 1968, 23:113-119.

10. Williams DI: Treatment of fungal infections by griseofulvin. The Chiropodist 1961, 16:149-154.

11. Anon: Be sure of your facts...(editorial). The Chiropodist 1959, 14:41-42

12. Anon: Liverpool convention 1969. The Chiropodist 1969, 24:22-25.

13. Anon: Silver jubilee convention. The Chiropodist 1970, 25:98-102.

14. Anon: The 1966 cambridge convention in retrospect. The Chiropodist 1966, 21:185-186

15. Anon: The norwich convention. The Chiropodist 1960, 15:351-354.

16. Anon: Forthcoming events and conventions. The Chiropodist 1956, 11:97-98.

17. Anon: Postgradute education (editorial). The Chiropodist 1976, 31:81-82.

18. Anon: Postgraduate education. The Chiropodist 1975, 30:245-246.

19. Hockaday TDR: Improving and extending chiropody services. The Chiropodist 1979, 34:337-338.

20. Anon: Diabetes. The Chiropodist 1980, 35:421-422.

21. Anon: Biomechanics. The Chiropodist 1983, 38:331-332.

22. Anon: The future (editorial). The Chiropodist 1984, 39:2-3.

23. Spencer C: Degree courses for chiropodists. The Chiropodist 1988, 43:131-133.

24. Marsh A: An investigation into the attitudes and expectations of final year chiropody students with particular reference to the national health chiropody service. The Chiropodist 1989, 44:108-113.

25. Bristow IR, Springett K: Podiatry, dermatology \& the UKPDA. British Assoc Dermatol Newsletter 2006, 9:22-23.

26. Burzykowski G, Molenberghs D, Abeck E, Haneke E, Hay RJ, Katsambas D, Roseeuw D, van der Kerkof P, van Aelst R, Marynissen G: High prevalence of foot diseases in Europe: results of the achilles project. Mycoses 2003, 46:496-505.

27. Thomson J: A dermatology service in a school of chiropody. The Chiropodist 1978, 33:100-101.

28. Lundberg GD: The role and function of professional journals in the transfer of information. Int J Technol Assess Health Care 1988, 4:51-58.

29. Krippendorf K: Content analysis. An introduction to its methodology. London: Sage; 1980.

30. Sproule W: Content analysis. In Social research methods: an australian perspective. Edited by Walter M. Melbourne: Oxford University Press; 2006:113-134.

31. Kondracki NL, Wellman NS, Amundson DR: Content analysis: review of methods and their applications in nutrition education. J Nutr Educ Behav 2002, 34:224-230.

32. Weber RP: Basic content analysis. London: Sage; 1990

33. Stemler S: An overview of content analysis. Pract assess res eval 2001, 17:7.

34. Farndon L, Vernon W, Potter J, Parry A: The professional role of the podiatrist in the new millennium:an analysis of current practice. Paper 1 . Br J Pod 2002, 5:68-72.

35. Krippendorff K: Content analysis:an introduction to its methodology. 2nd edition. London: Sage; 2004.

36. Krippendorff K: Estimating the reliability, systematic error, and random error of interval data. Educ Psychol Meas 1970, 30:61-70.

37. Hayes A, Krippendorff $K$ : Answering the call for a standard reliability measure for coding data. Commun Methods Meas 2007, 1:77-89.

38. Lombard M, Snyder-Duch J, Bracken C: Content analysis in mass communication: assessment and reporting on intercoder reliability. Human Commun Res 2002, 28:587-604.

39. Anon: The camden accord - the publications (editorial). J British Podiatric Med 1997, 52:169-170. 
40. Anon: Wart treatment by doctors. Search 1995, 68:9

41. Anon: Diabetes versus psoriasis. Search 1995, 62:6

42. Anon: What's new on the melanoma front? Search 1995, 60:9.

43. Anon: Psoriasis - new treatment products. Search 1993, 57:6.

44. George MA: A comparison of three treatments for fungal nail infection. Search 1991, 16:7-8.

45. Kerr T: Clinical trial of dermal therapy. Search 1994, 47:4-6.

46. Fisher A, Hay S: The motivation of the elderly with a problem of dry feet Search 1995, 62:3.

47. Joyce P: Post graduate podiatry education the oxford personnel training plan (PTP). Search 1996, 73:7.

48. Anon: Podium. British J Podiatric Med Surg 1995, 7:72

49. Galloway TR: Extension of access provision for a limited list of prescription only medicines (editorial). British J Podiatric Med Surg 1996, 8:19-20

50. Anon: International journals (editorial). Br J Pod 1999, 2:102.

51. Borthwick AM: 'Publish and be damned':disseminating contemporary podiatric research. Br J Pod 2004, 7:91-92

52. de Berker D, Dawber RPR: Diagnostic twists in neoplasms of the nail apparatus. Foot 1992, 2:73-77.

53. Smith AG: Inflammatory dermatoses of the feet. Foot 1992, 2:195-198.

54. Perks AGB, Miller G, Watson JS: Acral lentignous malignant melanoma in a diabetic foot:a plea for better education. Foot 1993, 3:83-85.

55. Smith AG: Skin tumours of the foot. Foot 1994, 4:175-179.

56. Heim M: Primary squamous carcinoma of the foot: a missed diagnosis. Foot 1996, 6:74-76.

57. Walzack JP, Klugman DJ: Squamous cell carcinoma of the hallux. Foot 1997, 7:33.

58. Montgomery F, Fioriti A: Piezogenic papules:treated by resection and hernial closure. Foot 1998, 8:171-172

59. Heim M, Wershavski M, Siev-Ner I, Azaria M: A late complication of erysipelas. Foot 1999, 9:203-205

60. Smith AG: Skin infections of the foot. Foot 1999, 9:56-59

61. Thoolen M, Ryan T, Bristow I: A study of the skin of the sole of the foot using high-frequency ultrasonography and histology. Foot 2000, 10:14-17.

62. Ramlogan D, Batta K, Byrne J: Pemphigus vulgaris presenting as chronic osteomyelitis of the foot. Foot 2001, 11:74-75.

63. Tytiun Y, lordache S, Grintal A, Velkes S, Salai M: Bacterial skin contamination and bacterial recolonization, after surgical preparation, in foot operations and prevalence of postoperative early wound infection: a prospective study. Foot 2005, 15:74-76.

64. Barkham MC, Smith AG, Harris S: Eccrine syringofibroadenoma. Foot 2006 16:198-200

65. O'Neill AC, Purcell EM, Regan PJ: Interdigital pilonidal sinus of the foot. Foot 2009, 19:227-228

66. Mann GC, Berry BL: Inopportune choice of treatment for verruca pedis. Foot 1996, 6:80-81.

67. Nicolopoulos CS, Tsioutis V, Nicolopoulos NS, Giannoudis PV: Clinical application of helium neon ( $632 \mathrm{~nm}$ ) plus infrared diode laser GaAIAs $(830 \mathrm{~nm})$ and CO2 laser in treatment of onychomycotic nails. Foot 1999 9:181-184.

68. Ricketti JC: Terbinafine/miconazole nitrate $2 \%$ tincture compound for the treatment of onychomycosis. Foot 2001, 11:21-23.

69. Davies KJ: Study to determine the efficacy of Clotrimazole $1 \%$ cream for the treatment of onychomycosis in association with the mechanical reduction of the nail plate. Foot 2006, 16:19-22.

70. Zalacain A, Ruiz L, Ramis G, Novel V, Ogalla JM, Calvo MA, Vinuesa T: Podiatry care and amorolfine: an effective treatment of foot distal onychomycosis. Foot 2006, 16:149-152.

71. Zatcoff R, Smith MS, Borkow G: Treatment of tinea pedis with socks containing copper impregnated fibers. Foot 2007, 18:136-141.

72. Bristow I, Walker N: Pulsed Dye laser for the treatment of plantar warts two case studies. Foot 1997, 7:229-230.

73. Powell J: Papillomavirus research and plantar warts. Foot 1998, 8:26-32.

74. Ellis MJH, Thomson CE: Consumer health information on the WWW: an evaluation of information on verrucae. Foot 2003, 13:130-135.

75. Bevans JS, Bosson G: A comparison of electrosurgery and sharp debridement in the treatment of chronic neurovascular, neurofibrous and hard corns. A pragmatic randomised controlled trial. Foot 2010, 20:12-17.
76. Anderson JM, Burrow JG: A small-scale study to determine the clinical effectiveness of electrosurgery in the treatment of chronic helomata (corns). Foot 2001, 11:189-198.

77. Mølgaard C, Lundbye-Christensen S, Simonsen O: High prevalence of foot problems in the danish population: a survey of causes and associations. Foot 2010, 20:7-11.

78. Vohra S, Bates AW, Baithun SI: A rare adnexal tumour of the hallux: malignant chondroid syringoma. Foot 1996, 6:175-177.

79. Padhiar N: Necrobiosis lipodica diabeticorum. Foot 1997, 7:47-51.

80. Barlow A, Parry E: Role of foot orthoses in the management of epidermolysis bullosa simplex. Foot 1999, 9:60-64.

81. Anderson PJ, Maloney DJL, Berry RB: Subcutaneous granuloma annulare. Foot 2000, 10:40-41

82. Smith RG: Shoe dermatitis: a review of current concepts. Foot 2008, 18:40-47.

83. Potter J, Potter MJ: The effect of callus removal on peak plantar pressures. Foot 2000, 10:23-26.

84. Potter J, Potter MJ: Regrowth patterns of plantar callus. Foot 2000, 10:144-148

85. Springett KP, Whiting MF, Marriott C: Epidemiology of plantar forefoot corns and callus, and the influence of dominant side. Foot 2003, 13:5-9.

86. Dagnall JC: A description of toenail matrix phenolisation 44 years before Boll's 1945 paper. Foot 1991, 1:51-55.

87. Paul AS, Ohiorenoya B, Meadows TH: Subungual exostosis presenting as an ingrowing toenail. Foot 1991, 1:125-126.

88. Goslin RW: A comparison of dilution and non-dilution of phenol with alcohol following nail avulsions. Foot 1992, 2:225-228.

89. Middleton A, Webb F: Toenail surgery for diabetic patients. Foot 1993, 3:109-113.

90. Heim M, Cohen I, Blankstein A, Hakerem D, Missre A, Dudkiewicz I: To ablate or not to ablate, that is the question. Foot 2001, 11:97-98.

91. Rounding C, Hulm S: Surgical treatments for ingrowing toenails. Foot 2001, 11:166-182.

92. Kaleel SS, labal S, Arbuthnot J, Lamont G: Surgical options in the management of ingrown toenails in paediatric age group. Foot 2007, $17: 214-217$.

93. Córdoba-Fernández A, Ruiz-Garrido G, Canca-Cabrera Á: Algorithm for the management of antibiotic prophylaxis in onychocryptosis surgery. Foot 2010, 20:140-145.

94. Davies $\mathrm{KJ}$ : Case report: pseudomonas aeruginosa infection following nail avulsion. Br J Pod 2000, 3:7-9.

95. Blake A: A postoperative comparison of partial nail avulsion using phenol and cryotherapy. Br J Pod 2005, 8:128-132.

96. Cumming S, Stewart S, Harborne D, Smith J, Broom H, Abbott A, Barton A A randomised controlled trial of phenol and sodium hydroxide in nail surgery. Br J Pod 2005, 8:123-127.

97. Day JC: A retrospective comparative study between HIV positive individuals and HIV negative individuals who have undergone partial nail avulsion surgery for onychocryptosis. Br J Pod 2006, 9:60-62.

98. Chapman C, Visaya G: Treatment of multiple verrucae by triggering cellmediated immunity - a clinical trial. Br J Pod 1998, 1:89-90.

99. Lelliott $P E$, Robinson $C$ : A retrospective study to evaluate verrucae regrowth following electrosurgery. Br J Pod 1999, 2:84-88.

100. Forster M: The use of electro-desiccation in the treatment of corns and verrucae. Br J Pod 2000, 3:64-66.

101. Mortimer A, Percivall A: A review of english senior school policies for the prevention and spread of verrua plantaris. Br J Pod 2001, 4:95-100.

102. Bristow I: Onychomycosis - a review of its presentation and treatment Br J Pod 2004, 7:64-67.

103. Brown $L A$, MacLarnon N: Do patients with untreated tinea pedis have concomitant fungal contamination within their footwear and hosiery. Br J Pod 2007, 10:134-138.

104. Swinscoe M: Podiatric parasitology. Br J Pod 1998, 1:106-108.

105. Weir HK, Carline T: Nail changes associated with the human immunodeficiency virus and acquired immunodeficiency syndrome-a case report. $\mathrm{Br} J \mathrm{Pod} 2000$, 3:9-12.

106. Wall B: Leishmaniasis - an overview of the disease and two case studies. Br J Pod 2001, 4:3-7.

107. Bours PW, Gilheany MF: Pyogenic granuloma. An atypical appearance in the foot. Br J Pod 2007, 10:57-59.

108. Hutchby M, Metcalfe S: Digital adenocarcinoma. Br J Pod 2007, 10:45-46. 
109. Ward R, Boon G: Case report. Lesser toe fibrolipoma in a patient with hereditary angioedema. Br J Pod 2007, 10:35-38.

110. Waddington AM, Hogg L: The surgical management of a subungual acral malignant melanoma:a case presentation and review of the literature. Br J Pod 2007, 10:166-170.

111. McCourt FJ: Normal plantar stratum corneum and callus. An analysis of fatty acids. Br J Pod 1998, 1:98-101.

112. Ingle M: The structure of keratin. Br J Pod 1999, 2:13-16.

113. Hashmi F: Non-enzymatic glycation and the development of plantar callus. Br J Pod 2000, 3:91-94

114. Plummer J, Springett K, Phillips G: Skin protection for use with caustics in podiatric practice: efficiency of a polymer paint. $\mathrm{Br} J \mathrm{Pod}$ 2004, 7:68-70.

115. Wilkinson A, Kilmartin T: A study into the long term effectiveness of electro-surgery for the treatment of corns. Br J Pod 1998, 1:138-141.

116. Rankin S, Swinscoe M: Alternative treatments and folk remedies in the treatment of warts. Br J Pod 2002, 5:12-14.

117. Bristow I, Acland K: Acral lentiginous melanoma of the foot: a review of 27 cases. J Foot Ankle Res 2008, 1:11.

118. Bristow I, de Berker D: Development of a practical guide for the early recognition of malignant melanoma of the foot and nail unit. J Foot Ankle Res 2010, 3:22.

119. Bristow IR, Bowling J: Dermoscopy as a technique for the early identification of foot melanoma: a review. J Foot Ankle Res 2009, 2:14.

120. Bristow IR, de Berker DA, Acland KM, Turner RJ, Bowling J: Clinical guidelines for the recognition of melanoma of the foot and nail unit. J Foot Ankle Res 2010, 3:25.

121. Spink M, Menz H, Lord S: Distribution and correlates of plantar hyperkeratotic lesions in older people. J Foot Ankle Res 2009, 2:8

122. Custance B: Clinical case study. Chiropodist 1990, 45:148-150.

123. Morris HJ: The treatment of multple and mosiac warts. Chiropodist 1989, $44: 2,4$

124. Russell M: Podiatric cryosurgery. Chiropodist 1990, 45:195-197.

125. Ashford R, Steele K: Granuflex E hydrocolloid dressing and Salactol in the treatment of verruca pedis:a randomised comparative study. J British Podiatric Med 1993, 48:107-113.

126. George MA: A comparison of three treatments for fungal nail infection. Chiropodist 1991, 46:134-135.

127. Foxall JD, Richards N: A review of podiatric management of onychomycosis (tinea unguium). J British Podiatric Med 1993, 48:53-56.

128. Mooney J: A review of current treatments for toenail mycoses. J British Podiatric Med 1993, 48:5-6.

129. Kingsford AC: Psoriasis. Chiropodist 1989, 44:35-39.

130. Beeson P: The clinical significance for chiropodists of recent advances made in the pathology and treatment of Psoriasis. Chiropodist 1990, 45:43-46.

131. Santos D: Pseudomonas aeruginosa infection of the nail:a case report. British J Podiatric Med 1997, 52:37-38.

132. Stepney E: Fungal nail infection - a new perspective. Podiatry Now 1998 $1: 221-223$

133. Swinscoe MJ: A case of onychomadesis associated with the use of cotrimoxazole in a female patient - a clinical report. J British Podiatric Med 1997, 52:30.

134. Thomson T: Malignant melanoma and squamous cell carcinoma on the foot. Four case reports. J British Podiatric Med 1996, 51:149-150

135. Haverstock B: Squamous cell carcinoma of the foot - a literature review and case report. British J Podiatric Med 1997, 52:76-79.

136. Sandilands S, Bligh MG: Subungual squamous cell carcinoma in the toe. A case report. J British Podiatric Med 1996, 51:5-6.

137. Stewart GA: Case study. Podiatry Now 1998, 1:415.

138. Kaura C, Francis BE: Clinical picture quiz 54. Podiatry Now 1999, 2:343

139. Kilmartin T: Clinical picture quiz 43. Podiatry Now 1998, 1:295.

140. Conway JJ: Clinical picture quiz 36. Podiatry Now 1998, 1:7-12.

141. Bristow I: Clinical picture quiz. Podiatry Now 2004, 7:26-30

142. Bristow I: Clinical picture quiz. Podiatry Now 2007, 10:46.

143. Bristow IR: Clinical picture quiz. Podiatry Now 2003, 6:13-34.

144. Bristow I, Banfield CC: Clinical picture quiz 47. Podiatry Now 1999, 2:87.

145. Bristow IR: Clinical picture quiz 58. Podiatry Now 2000, 3:191-211.

146. Bristow I: Clinical picture quiz 61. Podiatry Now 2000, 3:468-472.

147. Bristow IR: Clinical picture quiz 64. Podiatry Now 2001, 4:569.

148. Bristow I: Case study challenge (dermatology). Podiatry Now 2002, 5:117.
149. Danci T, Ersanli Z: Skin and connective tissue disorders in diabetes mellitus. J British Podiatric Med 1996, 51:151-154.

150. Denning DW, Evans EGV, Kibbler CC, Richardson MD, Roberts MM, Rogers TR, Warnock DW, Warren RE: Fungal nail disease:a guide to good practice (report of a working group of the british society for medical mycology). J British Podiatric Med 1996, 51:62-66.

151. Williams HC, Pottier A, Strachan D: The descriptive epidemiology of warts in British school children. J British Podiatric Med 1994, 49:171-176.

152. de Berker D: Management of nail unit wounds. British J Podiatric Med 1993, 48:175-177.

153. Butcher W, Papworth S, Parvin S, Darke S: Eighty-five consecutive cases of cellulitis:clinical features, management and implications for hospital care. Podiatry Now 2003, 6:26-29.

154. Tan BB, Lear JT, English JSC: Metastasis from carcinoma of the breast masquerading as chilblains. J British Podiatric Med 1997, 52:143.

155. Mattone-Volpe F: Cutaneous larva migrans infection in the pediatric foot. Podiatry Now 1998, 1:289-293.

156. Cox NH, Colver G, Paterson WD: Management and morbidity of cellulitis of the leg. Podiatry Now 1999, 2:292-295.

157. Baron S, Goulden V, Stables G: Atypical melanoma. Podiatry Now 2004, 7:22-23.

158. Department of Health: A first class service - quality in the new NHS. London: HMSO; 1998.

159. Department of Health: Continuing professional development. Quality in the new NHS. London: HMSO; 1999

160. Department of Health: Clinical governance - quality in the New NHS. London: HMSO; 1999

161. Potter MJ: Making progress with CPD and beyond (editorial). $\mathrm{Br} J \mathrm{Pod}$ 2002, 5:3.

162. Bristow IR: Core update course in dermatology. College of Podiatrists, Society of Chiropodists \& Podiatrists: Faculty of Podiatric Medicine; 2003.

163. Potter M: Faculty of podiatric medicine. Br J Pod 2003, 6:3.

164. Anon: HPC introduces CPD requirements for podiatrists from July 2006. Podiatry Now 2006, 9:6

165. Potter MJ: Continuing professional development and podiatry Now. Podiatry Now 2004, 7:22.

166. Bristow IR: Onychomycosis:guide to management. Podiatry Now 2004, 7:S1-S8.

167. Bristow I: Tinea pedis:diagnosis and management. Podiatry Now 2004 7:S1-S8.

168. Potter $M$, Bristow I: The treatment and management of verrucae using caustics. Podiatry Now 2006, 9:S1-S8.

169. Bristow IR, Ersser S: Inflammatory skin conditions: psoriasis and eczema. Podiatry Now 2004, 7:51-S8.

170. Penzer R: Emollients:selection and application. Podiatry Now 2005, 8:S1-S8.

171. Colver G: Cryosurgery in podiatric practice. Podiatry Now 2005, 8:S1-S8.

172. Percivall A: Principles of electrosurgery. Podiatry Now 2006, 9:s1-s8.

173. Ardern-Jones M: Malignant melanoma. Podiatry Now 2008, 11:s1-s8.

174. Bristow IR: Hyperkeratosis of the foot: part 1. Podiatry Now 2008, 11:S1-S8.

175. Anon: Continuing professional development - a new initiative (editorial). J British Podiatric Med 1996, 51:129-130.

176. Bristow I: Podiatric dermatology group to be launched at conference. Podium 2003, 1:10.

177. Neuendorf KA: The content analysis guidebook. London: Sage; 2002.

178. Springett K, Parsons S, Young M, Cheek E: The effect and safety of three corn care products. Br J Pod 2002, 5:82-86.

179. Potter J: The use of salicylic acid in the treatment of dorsal corn and callus. Br J Pod 2000, 3:51-55.

180. Potter J: Hyperkeratosis of the foot:part 2. Podiatry Now 2008, 11:S1-S8.

181. Hashmi F, Malone-Lee J, Hounsell E: Plantar skin in type 2 diabetes:an investigation of the biochemical and biomechanical nature of plantar epidermis (poster). Br J Pod 2004, 8:25.

doi:10.1186/1757-1146-6-21

Cite this article as: Bristow and Borthwick: Dermatology within the UK podiatric literature: a content analysis (1989-2010). Journal of Foot and Ankle Research 2013 6:21. 